Magister Hukum Fakultas Hukum Universitas Jenderal Soedirman

\title{
PENENTUAN KESEPAKATAN DIVERSI TERHADAP ANAK YANG BERKONFLIK DENGAN HUKUM PADA PENETAPAN PERKAR NO. 01 / PID.SUS-ANAK / 2017 / PN. CLP Oleh: BAUD HERU SETYO ${ }^{1}$
}

\begin{abstract}
ABSTRACK
Referring to Law no. 16 of 2004 which replaces Law no. 5 of 1991 on the Prosecutor's Office R.I., the Attorney as one of the law enforcement agencies are required to play a more role in upholding the rule of law, protection of public interest, human rights enforcement, and eradication of Corruption, Collusion and Nepotism (KKN). In the new Law of the Prosecutor's Office, the Public Prosecution Service as a state institution exercising state power in the prosecution field must perform its functions, duties and authority independently, irrespective of the influence of the power of government and the influence of other powers (Article 2 paragraph 2 of Law No. 16 Year 2004).

In carrying out its duties and authority, the AGO is led by the Attorney General who oversees six Junior Attorneys and 31 High Chief Prosecutors in each province. UU no. Law No. 16 of 2004 on the Attorney of the Republic of Indonesia also suggests that the AGO is in a central position with a strategic role in strengthening the nation's resilience. Because the AGO is in the axis and a filter between the investigation process and the examination process in the court as well as the executor of court decisions and decisions. Thus, the Prosecutor's Office is the controller of the case proceedings (Dominus Litis), since only the Attorney-General's office can determine whether a case may be brought to the Court or not based on valid evidence according to the Criminal Procedure Code.

The Cilacap District Attorney Obstacles faced in seeking diversion for child criminal cases with the first obstacle is that most of the criminal acts committed by the threat are more than 7 years imprisonment so that they can not be diversi- fied in accordance with Law Number 11 Year 2012 on Child Criminal Justice System, the second obstacle is the Cilacap State Attorney has 15 (fifteen) prosecutors and only 2 (two) prosecutors have the Decree from the Attorney General and have attended the training as a condition to be prescribed as the Child Procurator and have the right hear the children's case. Of course, with the number of 2 (two) public prosecutors is very less considering the high number of children's case volume in Cilacap District Court, so that prosecutors who do not have a decree are appointed to hear cases of children, the community's assessment that there is no firmness in law enforcement when resolved through diversion. In addition, the community's view of the diversion process tends to be negative which results in the occurrence of resentment and exclusion for children in conflict with the law and the community still wants to retaliate for the perpetrator by imposing penalties or criminal charges, the attitude of the victim's family who assumes a diversionary process will only free the child from responsibility for his deeds
\end{abstract}

\section{ABSTRAK}

Kejaksaan adalah lembaga negara yang melaksanakan kekuasaan negara, khususnya di bidang penuntutan. Sebagai badan yang berwenang dalam penegakan hukum dan keadilan, Kejaksaan dipimpin oleh Jaksa Agung yang dipilih oleh dan bertanggung jawab kepada Presiden. Kejaksaan Agung, Kejaksaan Tinggi, dan Kejaksaan Negeri merupakan

\footnotetext{
${ }^{1}$ POLRES CILACAP, baudherusetyo74@gmail.com, 081548999874
} 
kekuasaan negara khususnya dibidang penuntutan, dimana semuanya merupakan satu kesatuan yang utuh yang tidak dapat dipisahkan.

Mengacu pada Undang-Undang No. 16 Tahun 2004 yang menggantikan UU No. 5 Tahun 1991 tentang Kejaksaan R.I., Kejaksaan sebagai salah satu lembaga penegak hukum dituntut untuk lebih berperan dalam menegakkan supremasi hukum, perlindungan kepentingan umum, penegakan hak asasi manusia, serta pemberantasan Korupsi, Kolusi, dan Nepotisme (KKN). Di dalam UU Kejaksaan yang baru ini, Kejaksaan RI sebagai lembaga negara yang melaksanakan kekuasaan negara di bidang penuntutan harus melaksanakan fungsi, tugas, dan wewenangnya secara merdeka, terlepas dari pengaruh kekuasaan pemerintah dan pengaruh kekuasaan lainnya (Pasal 2 ayat 2 Undang-Undang Nomor 16 Tahun 2004).

Hambatan Kejaksaan Negeri Cilacap yang dihadapi dalam mengupayakan diversi untuk kasus pidana anak dengan hambatan pertama adalah karena sebagian besar tindak pidana yang dilakukan ancamannya lebih dari 7 tahun penjara sehingga tidak bisa dilakukan diversi sesuai dengan Undang-Undang Nomor 11 Tahun 2012 tentang Sistem Peradilan Pidana anak, hambatan yang kedua adalah Kejaksaan Negeri Cilacap mempunyai 15 (lima belas) orang Jaksa dan diantaranya hanya terdapat 2 (dua) orang jaksa yang sudah memiliki Surat Keputusan dari Jaksa Agung dan sudah mengikuti pelatihan sebagaimana yang menjadi syarat untuk dapat ditetepkan sebagai Penuntut Umum Anak dan berhak menyidangkan perkara anak. Tentunya dengan jumlah 2 (dua) orang Penuntut Umum Anak sangat kurang mengingat jumlah volume perkara anak yang cukup tinggi di Kejaksaan Negeri Cilacap, sehingga jaksa yang tidak memiliki Surat Keputusanpun ditunjuk untuk menyidangkan perkara anak, penilaian masyarakat bahwa tidak adanya ketegasan dalam penegakan hukum apabila diselesaikan melalui diversi. Selain itu pandangan masyarakat terhadap proses diversi cenderung negatif yang berakibat timbulnya dendam dan pengucilan bagi anak yang berkonflik dengan hukum serta masyarakat masih ingin melakukan pembalasan bagi pelaku dengan memberikan hukuman atau pidana, sikap keluarga korban yang beranggapan adanya proses diversi hanya akan membebaskan anak dari tanggung jawab atas perbuatannya.

\section{A. PENDAHULUAN}

Anak yang berhadapan dengan hukum adalah suatu istilah yang kerap digunakan ketika sesorang anak atau belum dewasa atau belum cukup umur melakukan suatu tindak pidana. Mengenai definisi anak dibawah umur kita merujuk pada Undang - Undang Nomor 11 Tahun 2012 tentang Sistem Peradilan Pidana Anak, khususnya pasal 1 Undang-undang Nomor 11 Tahun 2012 tentang Sistem Peradilan Pidana Anak dimana secara detail diuraikan yang mana anak di bawah umur sebagai anak yang telah berumur 12 tahun tetapi belum berumur 18 tahun, dan membedakan anak yang terlibat dalam suatu tindak pidana dalam tiga kategori:

a. Anak yang menjadi pelaku tindak pidana,

b. Anak yang menjadi korban tindak pidana (Anak Korban), dan

c. Anak yang menjadi saksi tindak pidana (Anak Saksi),

Sistem yang telah dibangun dalam Undang-undang No. 11 tahun 2012 tentang Sistem Peradilan Pidana Anak bukan hanya yang tertuang dalam konsideran saja melainkan juga tertuang 
dalam norma-norma sebagai perwujudan

nyata. Berikut ini adalah norma-norma yang menjadi penjelmaan semangat Undang-undang tersebut. :

a. Keadilan Restoratif ( Pasal 1 butir 6 Undang-Undang No. 11 tahun 2012 tentang Sistem Peradilan Pidana Anak)

Keadilan Restoratif adalah penyelesaian perkara tindak pidana dengan melibatkan pelaku, korban, keluarga pelaku/korban, dan pihak lain yang terkait untuk bersamasama mencari penyelesaian yang adil dengan menekankan pemulihan kembali pada keadaan semula, dan bukan pembalasan. Berdasarkan prinsip keadilan ini sesungguhnya telah mencerminkan tujuan dari sebuah pemidaan adalah win win solution atau mencari kebaikan bukan pembalasan. Karena dalam menghadapi anak yang berhadapan dengan hukum jikalau menganut prinsip pembalasan maka hak-hak anak akan terciderai oleh pandangan tersebut.

b. Diversi ( Pasal $6 \mathrm{~s} / \mathrm{d}$ pasal 15 Undang-Undang No. 11 tahun 2012 tentang Sistem Peradilan Pidana Anak )

Diversi adalah adalah pengalihan penyelesaian perkara Anak dari proses peradilan pidana ke proses di luar peradilan pidana.

Di mana dalam diversi ini pengupayaan penyelesaiaan perkara lebih diutamakan secara non penal karena diharapkan dengan menjauhakan anak dari penyelesaian penal akan lebih membuat anak terhindar dari dugaan, tuduhan, atau anggapan bahwa anak itu telah melakukan pelanggaran dalam salah satu ketentuan pidana dan juga menghindari anak dari beban psikologis akibat suasana pengadilan. Hal tersebut sesuai dengan semangat the best interest of child.

c. Asas-asas ( Pasal 2 UndangUndang No. 11 tahun 2012 tentang Sistem Peradilan Pidana Anak)

Asas-asas dalam sistem peradilan pidana merupakan bentuk publikasi pedoman dalam penyelesaian perkara anak yang sedang berhadapan dengan hukum. berikut ini adalah asas-asas yang dijadikan pedoman dalam sistem peradilan pidana anak :

1) Pelindungan

2) keadilan;

3) nondiskriminasi

4) kepentingan terbaik bagi Anak

5) penghargaan terhadap pendapat Anak

6) kelangsungan hidup dan tumbuh kembang Anak 
7) pembinaan dan pembimbingan Anak

8) Proporsional

9) perampasan kemerdekaan dan pemidanaan sebagai upaya terakhir; dan

10) penghindaran pembalasan.

d. Hak - hak ( Pasal 3 dan Pasal 4 Undang-Undang No. 11 tahun 2012 tentang Sistem Peradilan Pidana Anak )

Perumusan hak-hak dalam sistem perdilan pidana anak merupakan perwujudan nyata bahwa sistem peradilan pidana dewasa dan sistem peradilan pidana anak berbeda. Dan perbedaan ini adalah bukan diskriminasi melainkan perlakukan yang secara khusus terhadap anak.

e. Melindungi identitas anak dari publikasi di media masa ( pasal 19 Undang-Undang No. 11 tahun 2012 tentang Sistem Peradilan Pidana Anak )

Perlindungan identitas tentunya merupakan perwujudan nyata dari penjamin anak tidak terstigmakan atau tidak tercap sebagai seorang penjahat.

Istilah sistem peradilan pidana anak merupakan terjemahan dari istilah The Juvenile Justice System, yaitu suatu istilah yang digunakan searti dengan sejumlah institusi yang tergabung dalam pengadilan, yang meliputi Polisi, Jaksa Penuntut Umum, dan Penasehat hukum, lembaga pengawasan, pusat pusat penahanan anak serta fasilitas pembinaan anak. ${ }^{2}$

Merujuk pada latar belakang di atas, penulis tertarik untuk meneliti tentang peran kejaksaan dalam menentukan kesepakatan diversi terhadap anak yang berkonflik dengan hukum dengan rumusan masalah sebagai berikut :

1. Bagaimana proses penentuan kesepakatan diversi pada tingkat kejaksaan di Kejaksaan Negeri Cilacap pada Penetapan Perkara Nomor. 01/Pid.Susanak/2017/Pn.Clp?

2. Apakah hambatan-hambatan yang dihadapi dalam proses penentuan kesepakatan diversi di Kejaksaan Negeri Cilacap?

\section{B. PEMBAHASAN}

\section{Hasil Penelitian}

\section{a. Profil Kejaksaan Negeri Cilacap}

\footnotetext{
${ }^{2}$ Setya Wahyudi, "Penegakan Peradilan Pidana Anak dengen Pendekatan Hukum Progresif Dalam Rangka Pelindungan anak", Jurnal Dinamika Hukum, Vol. 9 No. 1 Edisi Januari 2009, Purwokerto: Fakultas Hukum Unsoed, Hlm. 29-30
} 


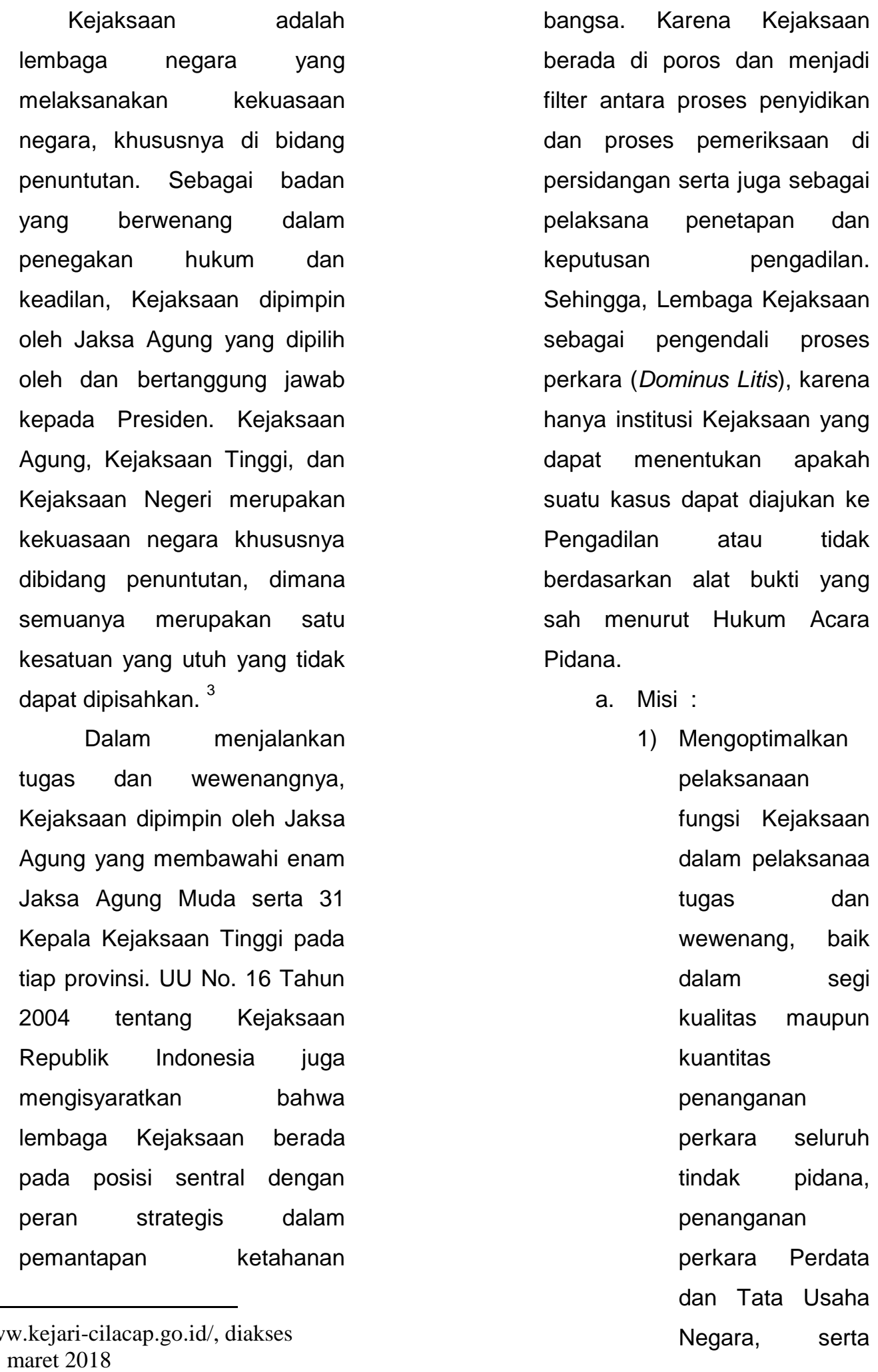

\footnotetext{
${ }^{3} \mathrm{http}: / / \mathrm{www}$. kejari-cilacap.go.id/, diakses tanggal 13 maret 2018
} 
pengoptimalan

kegiatan Intelijen

Kejaksaan, secara

profesional,

proposional dan

bermartabat

melalui penerapan

Standard

Operating

Procedure (SOP)

yang tepat,

cermat, terarah,

efektif, dan

efisien.

2) Mengoptimalkan

peranan bidang

Pembinaan dan

Pengawasan

dalam rangka

mendukung

pelaksanaan

tugas bidang-

bidang lainnya,

terutama terkait

dengan upaya

penegakan

hukum.

3) Mengoptimalkan

tugas pelayanan

publik di bidang

hukum dengan

penuh tanggung

jawab, taat azas,

efektif dan efisien, serta

penghargaan

terhadap hak-hak

publik;

4) Melaksanakan

pembenahan dan

penataan kembali

struktur organisasi

Kejaksaan,

pembenahan

sistem informasi

manajemen

terutama

pengimplementasi

an program

quickwins agar

dapat segera

diakses oleh

masyarakat,

penyusunan cetak

biru (blue print)

pembangunan

sumber daya

manusia

Kejaksaan jangka

menengah dan

jangka

panjangtahun

2025,

menerbitkan dan

menata kembali

manajemen

administrasi

keuangan, 
peningkatan

sarana dan

prasarana, serta

peningkatan

kesejahteraan

pegawai melalui

tunjangan kinerja

atau remunerasi,

agar kinerja

Kejaksaan dapat

berjalan lebih

efektif, efisien,

transparan,

akuntabel dan

optimal.

5) Membentuk

aparat Kejaksaan

yang handal,

tangguh,

profesional,

bermoral dan

beretika guna

menunjang

kelancaran

pelaksanaan

tugas pokok,

fungsi dan

wewenang,

terutama dalam

upaya penegakan

hukum yang

berkeadilan serta

tugas-tugas lainnya yang

terkait. ${ }^{4}$

Susunan Organisasi dan

Tata Kerja Kejaksaan Negeri

Cilacap adalah sebagai berikut :

SUSUNAN ORGANISASI DAN TATA

KERJA

KEJAKSAAN NEGERI CILACAP

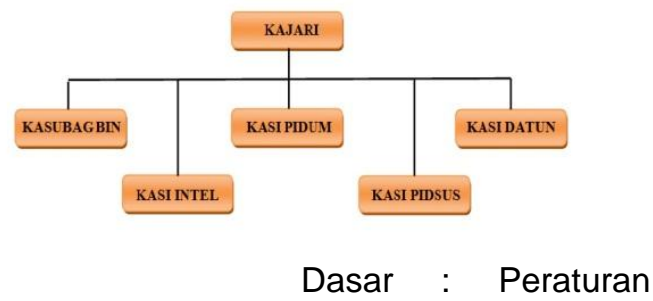

Presiden Republik Indonesia

Nomor 29 Tahun 2016 Tentang

Perubahan Atas Peraturan

Presiden Nomor 38 Tahun 2010

Tentang Organisasi Dan Tata

Kerja Kejaksaan Republik

Indonesia Jo. Peraturan Jaksa

Agung Nomor PER-

006/A/JA/07/2017 Tentang

Organisasi Dan Tata Kerja

Kejaksaan Republik Indonesia.

Kejaksaan Negeri cilacap dari tahun 2016 sampai dengan tahun 2018 telah melaksanakan beberapa kali melaksanaakan

${ }^{4}$ Sumber: Peraturan Jaksa Agung No:

011/A/JA/01/2010 tentang Rencana Strategis

Kejaksaan Republik Indonesia Tahun 2010-

2014 (diakses tanggal 28 Januari 2010) 
penyelesaian hukum terhadap

anak dengan cara diversi yaitu :

Tabel 1 (Data kasus Anak di Kejaksaan Negeri Cilacap)

\begin{tabular}{|c|c|c|c|c|}
\hline $\begin{array}{l}\mathrm{N} \\
\mathrm{O}\end{array}$ & $\begin{array}{l}\text { TAH } \\
\text { UN }\end{array}$ & $\begin{array}{c}\text { JUMLAH } \\
\text { KASUS } \\
\text { ANAK }\end{array}$ & $\begin{array}{l}\text { DIVER } \\
\text { SI }\end{array}$ & $\begin{array}{c}\text { KETERANGA } \\
\mathrm{N}\end{array}$ \\
\hline 1 & 2015 & 15 & --- & $\begin{array}{l}-4 \text { Kasus } \\
\text { Cabul } \\
\text { UUPA No. } \\
35 \text { Tahun } \\
2014 \\
-11 \text { Kasus } \\
\text { Pencurian } \\
\text { dengan } \\
\text { Pemberata } \\
\text { n. (Ps. } 363 \\
\text { KUHP) }\end{array}$ \\
\hline 2 & 2016 & 3 & $\begin{array}{c}1 \\
\text { (Gagal }\end{array}$ & $\begin{array}{l}-2 \text { Kasus } \\
\text { Cabul } \\
\text { UUPA No. } \\
35 \text { Tahun } \\
2014 \\
-1 \quad \text { Kasus } \\
\text { Pencurian } \\
\text { dengan } \\
\text { Pemberata } \\
\text { n Ps. } 363 \\
\text { KUHP } \\
\text { (Diversi } \\
\text { Gagal) } \\
\end{array}$ \\
\hline 3 & 2017 & 3 & $\begin{array}{c}1 \\
\text { (Berha } \\
\text { sil) }\end{array}$ & $\begin{array}{l}-1 \text { Kasus } \\
\text { Cabul } \\
\text { UUPA No. } \\
35 \text { Tahun } \\
2014 \\
-1 \quad \text { Kasus } \\
\text { Pencurian } \\
\text { Ps. } 362 \\
\text { KUHP } \\
\text { (Diversi } \\
\text { Berhasil) } \\
\text { - Kasus } \\
\text { Penyalahg } \\
\text { unaan } \\
\text { Narkoba } \\
\text { (UU } 35 \\
\text { Tahun } \\
\text { 2009) }\end{array}$ \\
\hline 4 & 2018 & 2 & --- & $\begin{array}{l}-1 \text { Kasus } \\
\text { Cabul } \\
\text { UUPA No. } \\
35 \text { Tahun } \\
2014 \\
\text { - 1Kasus } \\
\text { Penyalahg } \\
\text { unaan } \\
\text { Narkoba } \\
\text { (UU } 35 \\
\text { Tahun }\end{array}$ \\
\hline
\end{tabular}

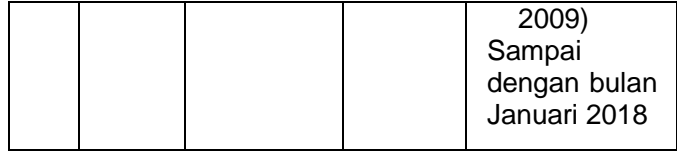

Melansir data di Kejaksaan Negeri Cilacap periode 2015-2018 menghitung ada 23 kasus anak yang berhadapan dengan hukum. Data itu meliputi perkara yang ada di wilayah Kabupaten Cilacap. Dari 23 kasus itu hanya 1 kasus yang berhasil diupayakan diversi pada tahap penyidikan. ${ }^{5}$

Hambatan Kejaksaan Negeri Cilacap yang dihadapi dalam mengupayakan diversi untuk kasus pidana anak menurut bapak Sudarsono Hari Prasetyo Jaksa di Kejaksaan Negeri Cilacap adalah karena sebagian besar tindak pidana yang dilakukan ancamannya lebih dari 7 tahun penjara sehingga tidak bisa dilakukan diversi. ${ }^{6}$

\section{Pembahasan}

1. Proses

Penentuan

Kesepakatan Diversi Di Tingkat Kejaksaan

Dalam penelitian ini, beberapa pihak yang terkait dalam

\footnotetext{
${ }^{5}$ Hasil wawancara dengan Sudarsono Hari Prasetyo jaksa di Kejaksaan Negeri Cilacap, tanggal 15 maret 2018

${ }^{6}$ Hasil wawancara dengan Sudarsono Hari Prasetyo jaksa di Kejaksaan Negeri Cilacap, tanggal 15 maret 2018
} 
proses diversi pada tahap penuntutan tersebut terdiri dari penuntut umum, Anak dan orangtua/walinya, korban, pembimbing kemasyarakatan, dan pekerja sosial professional.

a. Tersangka : MOLANA ARSAD

b. Orang tua

$\begin{array}{lll}\text { - Ayah : } & \text { ARIS } \\ \text { MOEJIYONO } & \\ \text { - } & \text { Ibu : } & \text { NUR } \\ & \text { SADIAWATI }\end{array}$

c. Korban : MUHAMMAD MAHENDRA

Proses pelaksanaan Diversi yang dilaksanakan di Kejaksaan Negeri Cilacap merupakan kewajiban yang dimiliki oleh Jaksa Penuntut Umum khususnya Penuntut Umum Anak pada tahap sebelum penuntutan di Pengadilan. Pelaksanaannya selain diatur dalam undangundang Sistem Peradilan Pidana Anak secara teknis dilaksanakan pula berdasarkan Peraturan Pemerintah nomor 65 tahun 2015 tentang Pedoman Pelaksanaan Diversi dan Penanganan Anak yang belum berumur 12 (dua belas) tahun. Pada Kejaksaan Negeri Cilacap harus menangani anak yang berkonflik dengan hukum harus mempertimbangkan kategori tindak pidana dan umur anak serta hasil penelitian pembimbing Kemasyarakatan dari BAPAS. Penuntut Umum Anak sebagai fasilitator bersama pembimbing kemasyarakatan dengan pelaku, korban, dan orang tua dipertemukan di dalam ruangan anak (RKA), melakukan musyawarah yang dimaksud untuk mendapatkan kesepakatan penyelesaian perkara.

Lawrence M. Friedman mengemukakan bahwa efektif dan berhasil tidaknya penegakan hukum tergantung pada sistem hukum yang mencakup tiga komponen atau sub-sistem, yaitu komponen struktur hukum (struktur of law), substansi hukum (substance of the law) dan budaya hukum (legal culture). Secara sederhana, teori Friedmann itu memang sulit dibantah kebenarannya. Namun, kurang disadari bahwa teori Friedman tersebut sebenarnya didasarkan atas perspektifnya yang bersifat sosiologis (sociological jurisprudence). 7 Yang hendak

7 M. Friedman, Lawrence, 1986, The Legal System. A Social Science Perspective, (New York: Russel Sage Foundation), hlm.15. 
diuraikannya dengan teori tiga sub-sistem struktur, substansi, dan kultur hukum itu tidak lain adalah bahwa basis semua aspek dalam sistem hukum itu adalah budaya hukum.

Subtansi hukum bisa dakatakan sebagai norma, aturan, dan perilaku nyata manusia yang berada pada sestem itu, di dalam subtansi hukum ada istilah " produk" yaitu suatu keputusan yang baru di susun dan baru di buat yang mana di sini di tekankan pada suatu hukum akan di buat jika melalui peristiwa terlebih dahulu. Seperti tertulis pada KUHP pasal 1 di tentukan "tidak ada suatu perbuatan pidana yang dapat di hukum jika tidak ada aturan yang mengaturnya", system ini sangat mempengaruhi system hukum di Indonesia. Peluang besar bagi seorang pelanggar hukum untuk lari dari sebuah sanksi dari tindakan yang menyalahi hukum itu sendiri. Sudah banyak kasus yang terjadi di Indonesia, yang di sebabkan lemahnya system yang sehingga para pelanggar hukum itu seolah

${ }^{8}$ Satjipto Rahardjo, 2008, Membedah Hukum Progresif, Penerbit Buku Kompas, Jakarta, hlm.5. meremehkan hukum yang ada.

Subtansi hukum juga mencakup hukum yang hidup (living law), bukan hanya aturan yang ada dalam kitab undang-undang (law books). Sebagai negara yang masih menganut sistem Civil Law Sistem atau sistem Eropa Kontinental (meski sebagaian peraturan perundang-undangan juga telah menganut Common Law). ${ }^{9}$

Substansi hukum menurut Friedman adalah :

"Another aspect of the legal system is its substance. By this is meant the actual rules, norm, and behavioral patterns of people inside the system ...the stress here is on living law, not just rules in law books". Aspek lain dari sistem hukum adalah substansinya. Yang dimaksud dengan substansinya adalah aturan, norma, dan pola perilaku nyata manusia yang berada dalam system itu. Jadi substansi hukum menyangkut peraturan perundang-undangan yang berlaku yang memiliki kekuatan yang mengikat dan

\footnotetext{
${ }^{9}$ M. Friedman, Lawrence. Op.cit, hlm.17.
} 
menjadi pedoman bagi aparat penegak hukum.

Tata Aturan Pelaksanaan

Diversi oleh Jaksa Penuntut Umum, meliputi: (1) Tata Cara Pelaksanaan Diversi oleh Jaksa Penuntut Umum Berdasarkan Undang-Undang No 11 Tahun 2012 tentang Sistem Peradilan Pidana Anak. Sistem peradilan pidana anak wajib mengupayakan Diversi yang berdasarkan atau mengutamakan pendekatan keadilan restoratif. Keadilan restoratif yang dimaksud yaitu proses di mana semua pihak terlibat dalam pelanggaran tertentu berkumpul bersama untuk memutuskan secara kolektif cara mengatasi konsekuensi pelanggaran dan implikasinya di masa mendatang.

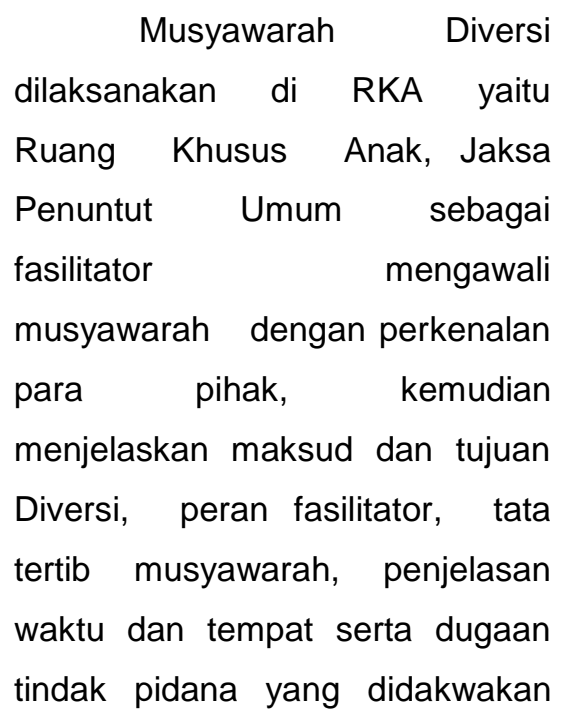

terhadap anak. Para pihak yang bersangkutan dalam pelaksanaan Diversi, di berikan kesempatan oleh fasilitator untuk menyampaikan pendapat, saran, dan tanggapan. Setelah dilaksanakannya Diversi kemudian dibuatlah Berita Acara Diversi yang ditandatangani fasilitator dan para pihak kemudian dilaporkan ke Kepala Kejaksaan negeri.

Teori Lawrence Meir Friedman yang Kedua : Struktur Hukum/Pranata Hukum: Dalam teori Lawrence Meir Friedman hal ini disebut sebagai sistem Struktural yang menentukan bisa atau tidaknya hukum itu dilaksanakan dengan baik. Struktur hukum berdasarkan UU No. 8 Tahun 1981 meliputi; mulai dari Kepolisian, Kejaksaan, Pengadilan dan Badan Pelaksana Pidana (Lapas). Kewenangan lembaga penegak hukum dijamin oleh undang-undang. ${ }^{10}$ Sehingga dalam melaksanakan tugas dan tanggung jawabnya terlepas dari pengaruh kekuasaan pemerintah dan pengaruh-pengaruh lain. Hukum tidak dapat berjalan atau

${ }^{10}$ Ali, Achmad, 2002, Keterpurukan Hukum di Indonesia, Chalia Indonesia, Jakarta, hlm. 8 
tegak bila tidak ada aparat penegak hukum yang kredibilitas, kompeten dan independen. Seberapa bagusnya suatu peraturan perundang-undangan bila tidak didukung dengan aparat penegak hukum yang baik maka keadilan hanya angan-angan. Lemahnya mentalitas aparat penegak hukum mengakibatkan penegakkan hukum tidak berjalan sebagaimana mestinya. Banyak faktor yang mempengaruhi lemahnya mentalitas aparat penegak hukum diantaranya lemahnya pemahaman agama, ekonomi, proses rekruitmen yang tidak transparan dan lain sebagainya. $^{11}$ Sehingga dapat dipertegas bahwa faktor penegak hukum memainkan peran penting dalam memfungsikan hukum. Kalau peraturan sudah baik, tetapi kualitas penegak hukum rendah maka akan ada masalah. Demikian juga, apabila peraturannya buruk sedangkan kualitas penegak hukum baik, kemungkinan munculnya masalah masih terbuka. ${ }^{12}$

Budaya hukum ini pun dimaknai sebagai suasana pikiran sosial dan kekuatan sosial yang menentukan bagaimana hukum digunakan, dihindari, atau disalahgunakan. Selanjutnya Friedman merumuskan budaya hukum sebagai sikap-sikap dan nilai-nilai yang ada hubungan dengan hukum dan sistem hukum, berikut sikap-sikap dan nilai-nilai yang memberikan pengaruh baik positif maupun negatif kepada tingkah laku yang berkaitan dengan hukum. Demikian juga kesenangan atau ketidak senangan untuk berperkara adalah bagian dari budaya hukum. Oleh karena itu, apa yang disebut dengan budaya hukum itu tidak lain dari keseluruhan faktor yang menentukan bagaimana sistem hukum memperoleh tempatnya yang logis dalam kerangka budaya milik masyarakat umum. Maka secara singkat dapat dikatakan bahwa yang disebut budaya hukum adalah keseluruhan sikap dari warga masyarakat dan sistem nilai yang ada dalam masyarakat yang akan menentukan bagaimana seharusnya hukum itu berlaku dalam masyarakat yang bersangkutan. ${ }^{13}$
${ }^{11}$ Ibid

${ }^{12}$ Ibid
${ }^{13}$ Ibid 
Mengenai budaya hukum, Friedman berpendapat :

"The third component of legal system, of legal culture. By this we mean people's attitudes toward law and legal system their belief in is the climinate of social thought and social force wich determines how law is used, avoided, or abused"

Kultur hukum menyangkut budaya hukum yang merupakan sikap manusia (termasuk budaya hukum aparat penegak hukumnya) terhadap hukum dan sistem hukum. Sebaik apapun penataan struktur hukum untuk menjalankan aturan hukum yang ditetapkan dan sebaik apapun kualitas substansi hukum yang dibuat tanpa didukung budaya hukum oleh orang-orang yang terlibat dalam sistem dan masyarakat maka penegakan hukum tidak akan berjalan secara efektif.

\section{Faktor-Faktor Penghambat} Jaksa Penuntut Umum Dalam Pelaksanaan Proses Diversi Di Kejaksaan Negeri Cilacap

a. Faktor Internal

$$
\begin{gathered}
\text { Faktor-faktor yang } \\
\text { menjadi alasan gagalnya }
\end{gathered}
$$

proses diversi pada tahap penuntutan di Kejaksaan Negeri Cilacap yaitu :

1) Penuntut Umum Anak yang Belum Cukup dan Memadai

2) Tidak Adanya Sosialisasi dari Kejaksaan Kepada Masyarakat Tentang Diversi

3) Inkonsistensi Penerapan Peraturan Perundang Undangan.

b. Faktor Eksternal

1) Pandangan Masyarakat Terhadap Perbuatan Tindak Pidana

2) Kurangnya Dukungan Dan Kerja Sama Antar Lembaga

\section{Penutup}

\section{SIMPULAN}

Berdasarkan hasil
pembahasan tentang proses penentuan diversi di Kejaksaan Negeri Cilacap maka disimpulkan bahwa Penyidik dalam melakukan upaya diversi yang kemudian berhasil ini dilakukan di Kejaksaan Negeri Cilacap pada tanggal 23 Februari 2017 melalui musyawarah dengan melibatkan tersangka anak dan orang tua tersangka, korban, Pembimbing 
Kemasyarakatan, dan Pekerja

Profesional. Musyawarah Diversi

dilaksanakan di RKA yaitu Ruang

Khusus Anak, Jaksa Penuntut

Umum sebagai fasilitator

mengawali musyawarah dengan

perkenalan para pihak, kemudian

menjelaskan maksud dan tujuan

Diversi, peran fasilitator, tata tertib musyawarah, penjelasan waktu dan tempat serta dugaan tindak pidana yang didakwakan terhadap anak. Para pihak yang bersangkutan dalam menentukan kesepakatan Diversi, di berikan kesempatan oleh fasilitator untuk menyampaikan pendapat, saran, dan tanggapan. Setelah dihasilkan kesepakatan dibuatlah Berita Acara Diversi yang ditandatangani fasilitator dan para pihak kemudian dilaporkan ke Kepala Kejaksaan Negeri Cilacap dan dimintakan Penetapan Ke Pengadilan Negeri Cilacap.

Hambatan Kejaksaan Negeri Cilacap yang dihadapi dalam mengupayakan kesepakatan diversi untuk kasus pidana anak adalah :

Sebagian besar tindak
pidana yang dilakukan
ancamannya lebih dari 7 tahun
penjara sehingga tidak bisa

dilakukan diversi sesuai dengan Undang-Undang Nomor 11 Tahun 2012 tentang Sistem Peradilan Pidana anak. Kejaksaan Negeri Cilacap mempunyai 15 (lima belas) orang Jaksa dan diantaranya hanya terdapat 2 (dua) orang jaksa yang sudah memiliki Surat Keputusan dari Jaksa Agung dan sudah mengikuti pelatihan sebagaimana yang menjadi syarat untuk dapat ditetepkan sebagai Penuntut Umum Anak dan berhak menyidangkan perkara anak. Tentunya dengan jumlah 2 (dua) orang Penuntut Umum Anak sangat kurang mengingat jumlah volume perkara anak yang cukup tinggi di Kejaksaan Negeri Cilacap, sehingga jaksa yang tidak memiliki Surat Keputusanpun ditunjuk untuk menyidangkan perkara anak, penilaian masyarakat bahwa tidak adanya ketegasan dalam penegakan hukum apabila diselesaikan melalui diversi.

Kurangnya pengetahuan Jaksa Penuntut Umum di Kejaksaan Negeri Cilacap tentang Standar Operasional Prosedur (SOP) pelaksanaan Diversi tindak pidana anak sehingga pada beberapa kasus anak tidak dapat 


\begin{abstract}
diselesaikan melalui Diversi di tingkat Kejaksaan Negeri Cilacap walauapun ancaman hukumannya dibawah 7 (tujuh) tahun.

Pandangan masyarakat terhadap proses diversi cenderung negatif yang berakibat timbulnya dendam dan pengucilan bagi anak yang berkonflik dengan hukum serta masyarakat masih ingin melakukan pembalasan bagi pelaku dengan memberikan hukuman atau pidana, sikap keluarga korban yang beranggapan adanya proses diversi hanya akan membebaskan anak dari tanggung jawab atas perbuatannya.
\end{abstract}

\title{
DAFTAR PUSTAKA
}

Ali, Achmad, 2002, Keterpurukan Hukum di Indonesia, Chalia Indonesia, Jakarta, hlm. 8

M. Friedman, Lawrence, 1986, The Legal System. A Social Science Perspective, (New York: Russel Sage Foundation),

Setya Wahyudi, "Penegakan Peradilan Pidana Anak dengen Pendekatan Hukum Progresif Dalam Rangka Pelindungan anak", Jurnal Dinamika Hukum, Vol. 9 No. 1 Edisi Januari 2009, Purwokerto : Fakultas Hukum Unsoed

Satjipto Rahardjo, 2008, Membedah Hukum Progresif, Penerbit Buku Kompas, Jakarta 